DOI: https://doi.org/10.15407/techned2021.06.003

\title{
SOME PHYSICAL PROCESSES IN THE APPLICATION OF THE ELECTRODYNAMIC METHOD OF METAL PROCESSING
}

\author{
Yu.M. Vasetsky ${ }^{*}$, I.P. Kondratenko ${ }^{* *}$ \\ Institute of Electrodynamics National Academy of Sciences of Ukraine, \\ pr. Peremohy, 56, Kyiv, 03057, Ukraine, \\ e-mail: vuriy.vasetsky@gmail.com; dep7ied@ukr.net
}

On the basis of the developed analytical mathematical model of non-stationary process of local electrodynamic treatment of metal structures, especially welded joints, and estimation of the main dynamic, electrophysical and thermal characteristics of the process are considered. The characteristics of the motion of the electrode, the distribution of the pulse current in the metal plate, the heating of the metal are found and analyzed. The conclusion about the possibility of realization of devices with simultaneous supply of current pulses of necessary parameters on the shock electromagnetic element and through an electrode to the metal plate to achieve the effect of electroplasticity is made. References 19 , figures 9, tables 2 .

Key words: electrodynamic treatment of metal products, pulse current distribution, motion equation, electroplasticity effect, heating of metal by pulse currents.

Introduction. Scientific and experimental studies have shown that the treatment of metallic materials, including welds by pulsed electric current and pulsed electromagnetic field has a positive effect on reducing the stress-strain states of metal structures $[1,2]$. Pulsed electromagnetic field creates a magnetic pressure in the metal, which is close to the yield strength of the material, which reduces stress levels and increases the plasticity of the metal. Another means of influence is the use of the effect of electroplasticity, which occurs provided that the current density in the metal is not less than a certain value, which, for example, for aluminum alloys reaches $10^{9} \mathrm{~A} / \mathrm{m}^{2}$. The influence of high-density pulsed electric current and of the associated effect of electroplasticity occurs both in the material of high-strength steels [3] and in some non-ferrous metals and their alloys: aluminum, magnesium [4 6], zirconium [7] and others.

Achieving the required level of current density in the metal is carried out using various methods. Moreover, as noted in [8], the transients of the dynamic mode, which are associated with the type of power supply, are important. Non-contact induction method current input in a limited area of the weld [9, $10]$ is characterized by relative simplicity of use and low energy consumption. A promising way to improve the mechanical and operational characteristics of welded joints is electrodynamic treatment - a new method based on the simultaneous local action of pulsed electrodynamic force and pulsed electric current flowing due to direct contact $[11,12]$. It is due to the flow of high-density pulsed current that the realization of the electroplastic effect becomes possible [2].

The principle of operation of the device for electrodynamic processing is to apply simultaneously a current pulse $I_{0}(t)$ to the metal electrode and a current pulse $I_{k}(t)$ to the inductor coil with the number of turns $n$. The pulse magnetic field of the inductor coil induces the eddy currents in the metal

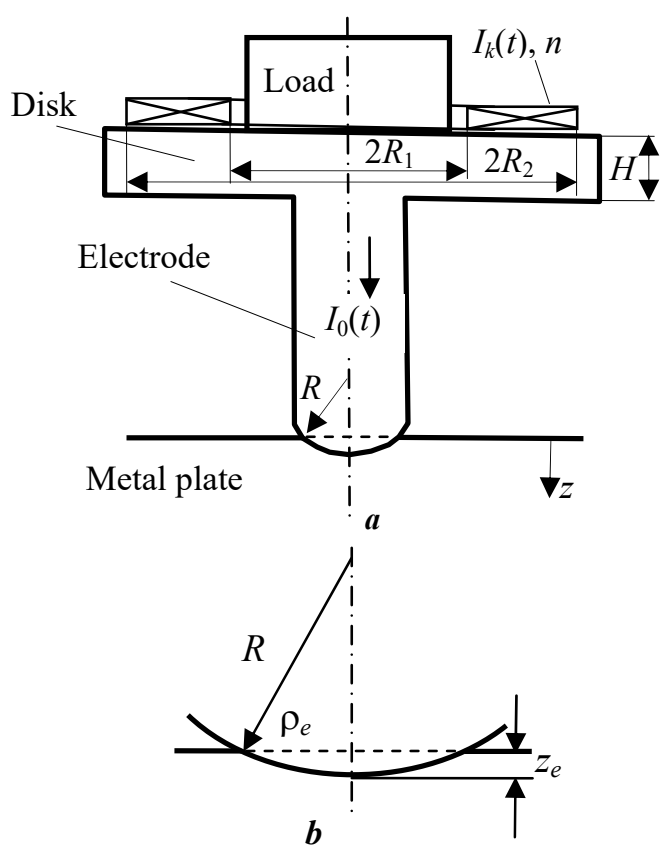

Fig. 1

(C) Vasetsky Yu.M., Kondratenko I.P., 2021

ORCID ID: ${ }^{*}$ https://orcid.org/0000-0002-4738-9872; ** https://orcid.org/0000-0003-1914-1383 
disk and as a result the electrodynamic force acts in the disk connected to the electrode (Fig. 1, a). (Hereinafter, in cases where the disk with the electrode is considered as a single object, it will be called a "shock element").

The shock element by mass $m$ under the action of electromagnetic force creates a dynamic impact on the metal plate. This leads to the deepening of the electrode into the metal and to an increase in the area of contact of the electrode with the plate (Fig. 1, $b$ ). The load with the mass $M$ is designed to create the pressure of the electrode to the metal plate at the initial time.

The application of local electrodynamic treatment of metal structures, including welds, requires the assessment of interrelated electrodynamical, electrophysical and thermal processes. Each of these processes affects the mechanical properties of the metal in local area.

Hence, the purpose of the work is to develop a mathematical model of the non-stationary process of electrodynamic processing of metal structures and finding on its basis the basic electrodynamical, electrophysical and thermal characteristics of the process. We will estimate the process characteristics using certain simplifications, which allows us to apply analytical methods of analysis. This approach makes it possible to analyze the overall impact of the main factors and it is a feature of this study.

\section{Mathematical model and analytical calculation method.}

A. Parameters of current pulses and electromagnetic processes in the disk. In the analytical model the currents $I_{k}(t)$ and $I_{0}(t)$ will be described as exponentially decaying oscillating pulses:

$$
I(t)=I_{m} e^{-\alpha t} \sin \beta t .
$$

The parameters of the pulse $I_{m}, \alpha, \beta$ are related to
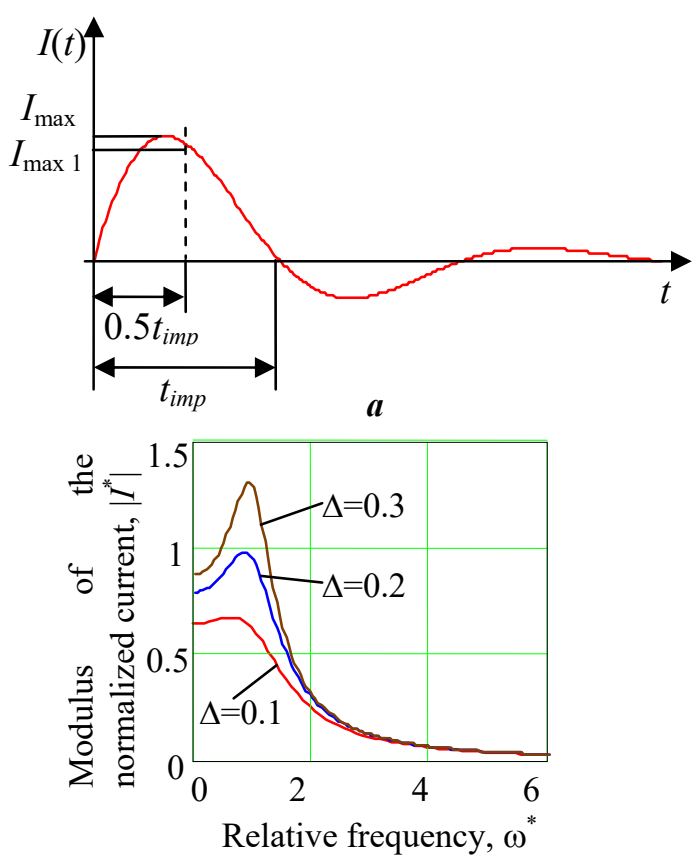

$b$

Fig. 2 other characteristics that can be considered given (Fig. 2, $a$ ): the pulse time $t_{i m p}$, which will be defined as the duration of the first half-wave; the maximum value of the current pulse $I_{\max }$ or the amplitude value of the first half-wave $I_{\max 1}$; the ratio of the amplitudes of the second half-wave to the first one $\Delta$, which should be negligible. Hence we have the relationship between the parameters of the pulse and the specified characteristics:

$$
\begin{gathered}
\beta=\pi / t_{\text {imp }}, \quad \Delta=e^{-\alpha \frac{3 \pi}{2 \omega}} / e^{-\alpha \frac{\pi}{2 \omega}} \text { from here } \alpha=\frac{\beta}{\pi} \ln \frac{1}{\Delta}=\frac{1}{t_{i m p}} \ln \frac{1}{\Delta}, \\
I_{\max 1}=I_{m} e^{-\alpha \frac{t_{i m p}}{2}} \text { from here } I_{m}=I_{\max 1} e^{\frac{1}{2} \ln \frac{1}{\Delta}}=\frac{I_{\max 1}}{\sqrt{\Delta}} .
\end{gathered}
$$

Note that the parameter $\beta$ is uniquely related to the pulse time $t_{i m p}$ and therefore it can also be considered as a given parameter.

Since pulse processes are considered, and some estimates are made for characteristic frequencies, the possibility of their use will be evaluated by parameters that are determined by the part of energy of the frequency spectrum in

the selected frequency limits.

The complex-value amplitude of frequency spectrum $\dot{I}(i \omega)$ of the current pulse (1) is the following

$$
\dot{I}(i \omega)=\frac{I_{m} \beta}{(\alpha+i \omega)^{2}+\beta^{2}} .
$$

In Fig. 2, $b$ shows the dependence of the modulus of the normalized current $\left|\dot{I}^{*}(i \omega)\right|=\beta|\dot{I}(i \omega)| / I_{m}$ on the relative frequency $\omega^{*}=\omega / \beta$ for the three values of the parameter $\Delta$. It is seen that for this type of pulse, provided that the second half-wave is small (small value of the parameter $\Delta$ ), there is no sharp maximum of the frequency spectrum nearby $\omega / \beta \approx 1$ and low frequencies are significantly present in the spectrum. 
Peculiarities of electromagnetic processes taking into account eddy currents in conducting body are determined by the ratio of the field penetration depth $\delta=\sqrt{2 /\left(\omega \mu \mu_{0} \gamma\right)}$ and the corresponding size of the body $H$ [14] (here $\gamma$ is specific conductivity, $\mu$ is relative magnetic permeability of the medium). The condition of a strong skin effect, when the field completely decays in the thin surface layer of the body, is fulfilled for all frequencies of the spectrum, starting from a certain frequency $\omega \geq \omega_{1}$. On the contrary, the condition of weak skin effect, when the induced currents in the conducting body almost do not affect the field of external sources (magnetic field of the inductor), is fulfilled for low frequencies that do not exceed a certain value $\omega \leq \omega_{2}$ [15]. In the device under consideration, it is necessary to create a repulsive force of interaction between the inductor and the disk. Therefore for the disk it is inexpedient to use the materials which are magnetized, and further it is accepted that $\mu=1$.

The electromagnetic interaction between the inductor and the metal disk in the device in Fig. 1, $a$ under the condition of strong skin effect is much greater than with weak skin effect. This is the first reason why you should try to get parameters with strong skin effect. The second reason is the distribution of eddy currents and, accordingly, the electromagnetic forces of the interaction between the inductor and the disk.

So, under the condition of strong skin effect, the surface current density $j_{S}(t)=B_{k}(t)\left(2 \mu_{0}\right)^{-1}$ changes in time according to the same law as the magnetic flux density $B_{k}(t)$ created by the inductor at the body surface [9]. That is, during the time, the surface density of electromagnetic forces, or otherwise, the magnetic pressure $F_{S}=B_{k}(t) j_{S}(t)=\left[2 B_{k}(t)\right]^{2}\left(2 \mu_{0}\right)^{-1}$ does not change sign and the direction of action.

A different distribution of eddy currents and electromagnetic forces occurs with weak skin effect. In this case, the induced electric field and the density of eddy currents in the conducting body are proportional to the time derivative of the induction of the external magnetic field and, accordingly, of the inductor current $j \sim \frac{\partial B_{k}}{\partial t} \sim \frac{\partial I_{k}}{\partial t}$. The components of the vector of the electromagnetic forces volume density change sign over time, i.e. change the direction of action to the opposite. Moreover, since $\int_{0}^{t_{\text {imp }}} I_{k} \frac{d I_{k}}{d t} d t=0$, the total mechanical impulse transmitted to the conducting body is equal to zero. Due to this feature of the action of electromagnetic forces to the disk, the use of system parameters with weak skin effect is undesirable, since it can lead to a rebound of the electrode from the metal plate and the appearance of a spark when current flows through the electrode.

The estimation of the cutoff frequencies $\omega_{1}$ and $\omega_{2}$ is performed by a parameter determined by parts of energy of the frequency spectrum of the current pulse: $\omega_{1}$ under the condition of strong skin effect for each frequency $\omega \geq \omega_{1}$ and $\omega_{2}$ under the condition of weak skin effect for all frequencies $\omega \leq \omega_{2}$ :

$$
d_{1}\left(\omega_{1}\right)=\int_{\omega_{1}}^{\infty}|\dot{I}(i \omega)|^{2} d \omega / \int_{0}^{\infty}|\dot{I}(i \omega)|^{2} d \omega, \quad d_{2}\left(\omega_{2}\right)=\int_{0}^{\omega_{2}}|\dot{I}(i \omega)|^{2} d \omega / \int_{0}^{\infty}|\dot{I}(i \omega)|^{2} d \omega
$$

The characteristics $d_{1}\left(\omega_{1}\right)$ for the pulse (1) are shown in Fig. 3, a. As can be seen, for pulses that

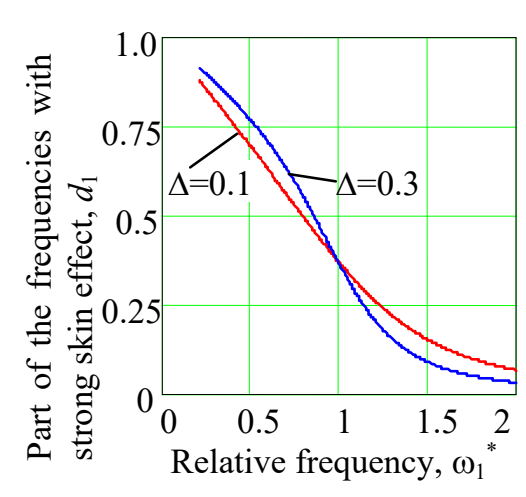

$a$

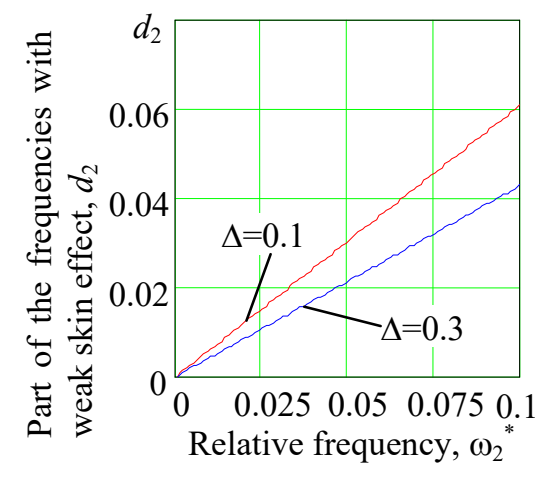

b

Fig. 3 quickly decaying over time $t_{i m p}$, the characteristics are weakly dependent on the parameter $\Delta$. Choosing, for example, for $\Delta=0.1$ the value of the cutoff frequency $\omega_{1}^{*}=\omega_{1} / \beta=0.5$, we obtain that the part of all frequencies in the spectrum by the parameter $d_{1}\left(\omega_{1}\right)$ is $d_{1}=0.69$. In Fig. $3, b$ shows the dependence of another indicator $d_{2}\left(\omega_{2}\right)$ on the cutoff frequency 
$\omega_{2}^{*}=\omega_{2} / \beta$ for the weak skin effect in the low frequency range of the pulse spectrum (3).

The cutoff frequency $\omega_{1}$ allows to determine the minimum thickness $H=k_{1} \delta\left(\omega_{1}\right)$ of the conducting body (for the device in question this is the thickness $H$ of the metal disk), when the strong skin effect occurs. Usually, we can assume that the field is almost completely decays in the surface layer at $k_{1}=3$, i.e. the condition of strong skin takes place.

The condition of weak skin effect for a body with characteristic size $H$ compared to the penetration depth can be written as $H=k_{2} \delta\left(\omega_{2}\right)$, where $k_{2}<1$. Comparing the conditions of the strong and weak skin effect for the body thickness $H$, we obtain that the ratio of the cutoff frequencies in the frequency spectrum of the current pulse is:

$$
\frac{\omega_{2}}{\omega_{1}}=\frac{\omega_{2}^{*}}{\omega_{1}^{*}}=\frac{k_{2}^{2}}{k_{1}^{2}} .
$$

From (5) it follows that the cutoff frequencies are significantly different. So, for the previous example $\omega_{1}^{*}=0.5$ and $k_{1}=3$, the relative value of the cutoff frequency $\omega_{2}^{*}$ will be $\omega_{2}^{*}<0.056$. That is, according to the entered indicator, the part of frequencies at which the weak skin effect is appeared is insignificant. However, there is a frequency range $\omega_{2}<\omega<\omega_{2}$ at which electromagnetic processes in the conducting media do not have pronounced signs of strong or weak skin effect. At the same time, for the selected disk thickness $H$, the frequencies $\omega \geq \omega_{1}$ remain the predominant component. Therefore, in the future we will assume that the choice of disc material and its size $H$ is based on parameters $\omega_{1}^{*}=0.5$, $k_{1}=3$ and the strong skin effect takes place in the disc.

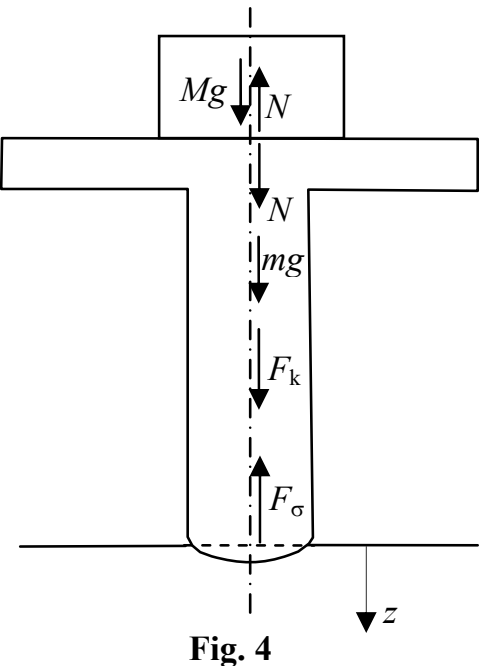

Fig. 4

$B$. The forces acting to the device shock element consist of the gravity forces of the load $M g$ and the shock element itself $m g$, as well as forces from the inductor $F_{k}$ (Fig. 4). An oppositely directed force $F_{\sigma}$ is associated with the mechanical stresses in the plate. In addition to these forces in Fig. 4 shows the force $N$ of mechanical interaction between the load and the shock element. All these forces determine the movement dynamics of the shock element. We provide specific expressions that define forces.

In an axisymmetric system, the electromagnetic force $F_{k}(t)$ acting to the metal disk in the vertical direction is defined by the interaction of the radial component of the magnetic flux density $B_{\rho}$ of the inductor with the surface density of the azimuthal directional induced current $j_{S}$. Assuming that the thickness of the disk and winding is much smaller than the radial size of the inductor $2 R_{2}$, in the approximate analytical model we can assume that the radial component of the magnetic field $B_{\rho}$ and the surface density $j_{S}$ do not change within the inductor size $R_{2}-R_{1}$. Given that with the strong skin effect $j_{S}=2 B_{k}=2 I_{k}(t) n /\left[\mu_{0}\left(R_{2}-R_{1}\right)\right]$, where $n$ is the number of turns of the winding, we find the force acting to the disk:

$$
F_{k}(t)=B_{k} j_{S} \pi\left(R_{2}^{2}-R_{1}^{2}\right)=\frac{\mu_{0} \pi}{2} \frac{R_{2}+R_{1}}{R_{2}-R_{1}} I_{k}^{2}(t) n^{2} .
$$

We assume that under the action of the electrode pressure in the metal plate there are only plastic deformations, for which the mechanical stresses are characterized by the condition $\sigma=$ const . In this case, the oppositely directed force acts on the electrode:

$$
F_{\sigma}=\sigma \pi \rho_{e}^{2},
$$

where at $z_{k}<R$ (Fig. $1, b$ ) the radius of the dent is $\rho_{k} \approx \sqrt{2 R z_{k}}$.

C. Equation of motion and its solution. Under the action of all forces in the first stage, the shock element together with the load moves in the direction of the axis $z$. In the second stage, the load lags behind the shock element, which continues to move. The dent deepens and increases in radius.

The equation of accelerated motion in the first stage is: 


$$
(M+m) \frac{d^{2} z_{1}}{d t^{2}}+2 \pi R \sigma z_{1}=(M+m) g+F_{k}(t)
$$

where in the first stage the value $z_{e}$ is marked as $z_{1}, g$ is acceleration of gravity. The initial conditions are as follows:

$$
z_{1}(t=0)=z_{0}=\frac{(M+m) g}{2 \pi \sigma R},\left.\quad \frac{d z_{1}}{d t}\right|_{t=0}=v_{0}=0 .
$$

The end time of the first stage is defined as $\frac{d^{2} z_{1}}{d t^{2}}=g$.

We rewrite equation (8) in the form where all functions are presented explicitly:

$$
\frac{d^{2} z_{1}}{d t^{2}}+a_{1}^{2} z_{1}=g+\frac{b_{1}}{2} e^{-2 \alpha_{k} t}\left(1-\cos 2 \beta_{k} t\right)
$$

where

$$
a_{1}^{2}=\frac{2 \pi \sigma R}{M+m}, \quad b_{1}=\frac{\mu_{0} \pi n^{2}}{2(M+m)} \frac{R_{2}+R_{1}}{R_{2}-R_{1}} .
$$

We will look for the analytical solution of the equation in the form of the sum of the general solution of the homogeneous $\mathrm{z}_{1 \mathrm{~g}}$ and partial solution of the inhomogeneous $z_{1 p}$ equations $z_{1}=\mathrm{z}_{1 g}+z_{1 p}[16]$.

The general solution of homogeneous equation is:

$$
z_{1 g}=A_{11} \sin a_{1} t+A_{12} \cos a_{1} t .
$$

The right-hand member of inhomogeneous equation (10) is the sum of three functions of special kind $z_{1 p}=z_{1 p 1}+z_{1 p 2}+z_{1 p 3}$ for which partial solutions are known [13]:

$$
\mathrm{z}_{1 p 1}=\frac{g}{a_{1}^{2}}=z_{0}, \quad \mathrm{z}_{1 p 2}=\frac{b_{1}}{2} \frac{e^{-2 \alpha_{k} t}}{4 \alpha_{k}^{2}+a_{1}^{2}}, \quad \mathrm{z}_{1 p 3}=-\frac{b_{1}}{2} \operatorname{Re}\left[\frac{e^{-2 \alpha_{k} t+i 2 \beta_{k} t}}{\left(-2 \alpha_{k}+i 2 \beta_{k}\right)^{2}+a_{1}^{2}}\right],
$$

where $i$ is imaginary unit.

The constants $A_{11}$ and $A_{12}$ in (12) are defined from the initial conditions (9):

$$
A_{12}=z_{0}-z_{1 p}(0)=-z_{1 p 1}(0)-z_{1 p 2}(0), A_{11}=-\frac{1}{a_{1}}\left(\left.\frac{d z_{1 p 1}}{d t}\right|_{t=0}+\left.\frac{d z_{1 p 2}}{d t}\right|_{t=0}\right) .
$$

The presented solution is valid until $t_{1 e}$ when the shock element is detached from the load. At this point in time, the position of the shock element is $z_{1}\left(t_{1 e}\right)=z_{1 e}$ and its speed is $v_{1 e}=\left.\left(d z_{1} / d t\right)\right|_{t=t_{1 e}}$.

In the second stage, the equation of motion remains similar (1) with no mass $M$. The initial conditions at the moment of time $t=t_{1 e}$ have the following meanings $z_{20}=z_{1 e}, v_{20}=v_{1 e}$.

The general solution of the homogeneous and partial solution of the inhomogeneous equations is also similar to (12) and (13) with the replacement of the coefficients $a_{1}$ and $b_{1}$ by $a_{2}$ and, $b_{2}$ in which there is no mass $M$. In the second stage, the constants $A_{21}$ and $A_{22}$ in the general solution of the homogeneous equation, in contrast to the first stage, are taken into account the nonzero value of the velocity at the initial moment of time:

$$
\begin{aligned}
& A_{21} \sin a_{2} t_{1 e}+A_{22} \cos a_{2} t_{1 e}=z_{20}-z_{2 p 0}-z_{2 p 1}\left(t_{1 e}\right)-z_{2 p 2}\left(t_{1 e}\right), \\
& a_{2} A_{21} \cos a_{2} t_{1 e}-a_{2} A_{22} \sin a_{2} t_{1 e}=v_{20}+\left.\frac{d z_{2 p 1}}{d t}\right|_{t=t_{1 e}}+\left.\frac{d z_{2 p 2}}{d t}\right|_{t=t_{1 e}} .
\end{aligned}
$$

The process ends at a time $t_{2 e}$ determined by the stop moving $d z_{k} / d t=0$.

D. Current pulse in the metal plate. For a metal plate with high electrical conductivity $\gamma$, for example aluminum, and current pulse parameters used in experiments [12], we can assume that the field penetration depth into the plate for the characteristic frequencies of the current pulse significantly exceeds the radius of the dent $\delta>>\rho_{e}$. It follows that within the distances $r<\delta$ from the center of the dent, the 

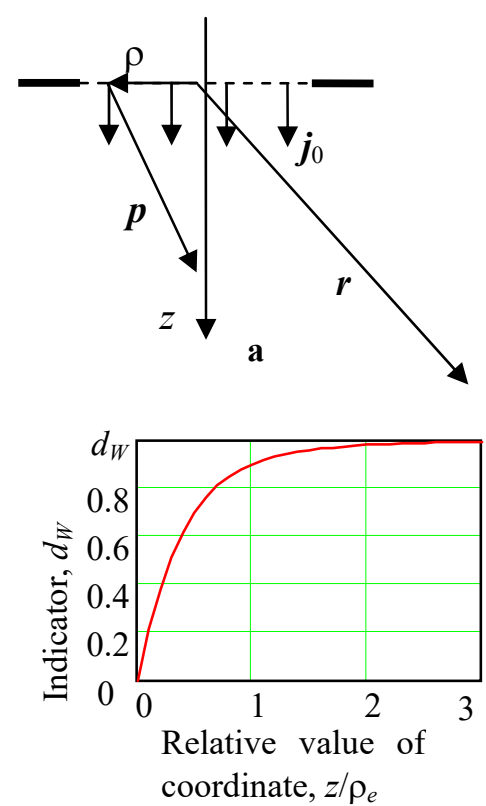

b

Fig. 5

electric field can be considered as potential [13], and the distribution of current density in the plane of the dent is homogeneous $\boldsymbol{j}_{0}=I_{0}(t) /\left(\pi \rho_{e}^{2}\right)=\gamma \boldsymbol{E}_{0}$. We assume that current density $\boldsymbol{j}_{0}$ is given on a flat surface (Fig. 5), neglecting the depth of the dent.

The problem is to determine the distribution of current density in the metal plate $\boldsymbol{j}$ and the thermal-power density (volumetric density of heat sources) released during the flow of current $w=j^{2} / \gamma$, as well as the increase in temperature $\Delta T$ of the metal near the dent.

The potential, defined in the usual way $\boldsymbol{E}=\boldsymbol{j} / \gamma=-\operatorname{grad} \varphi$, is found as a solution of the Neumann problem for the Laplace equation in the lower half-space, where the normal derivative of the potential $\frac{\partial \varphi}{\partial z}=-\frac{j_{0}}{\gamma}$ is given on the surface at $\rho \leq \rho_{e}$, and on the other part of the surface it is given $\frac{\partial \varphi}{\partial z}=0[17,18]$. The problem has a simple solution in the form of a field of a simple layer of sources that are evenly distributed within the circle $\rho \leq \rho_{e}$. However, the formulation of the boundary value problem is simplified in the sense that within the circle $\rho \leq \rho_{e}$ it assumes the presence of some tangent component of the field.

The potential on the axis $z$ is as follows:

$$
\varphi=\frac{j_{0}}{2 \pi \gamma} \int_{S} \frac{1}{\sqrt{\rho^{2}+z^{2}}} d S=\frac{j_{0}}{\gamma}\left(\sqrt{\rho_{e}^{2}+z^{2}}-z\right) .
$$

Hence the current density on the axis $z$ is equal to:

$$
j(z, t)=-\gamma \frac{\partial \varphi}{\partial z}=\frac{I_{0}(t)}{\pi \rho_{e}^{2}}\left(1-\frac{z}{\sqrt{\rho_{e}^{2}+z^{2}}}\right) .
$$

The thermal-power density is written as:

$$
w=\frac{j^{2}}{\gamma}=\frac{I_{0}^{2}(t)}{\pi^{2} \gamma \rho_{e}^{4}}\left(1-\frac{z}{\sqrt{\rho_{e}^{2}+z^{2}}}\right)^{2} .
$$

From (17) it follows that at distances $z>\rho_{e}$ when the values $\left(\rho_{e} / z\right)^{2}$ can be neglected, the current density decays approximately as the second power of the distance from the surface $j \approx I_{0}(t) /\left(2 \pi z^{2}\right)$. Accordingly, the value $w(z, t)$ in (18) decreases much faster - inversely proportional to the fourth power of the distance $w \approx I_{0}^{2}(t) /\left(\pi^{2} \gamma z^{4}\right)$. The functions decrease along an arbitrary radial direction (Fig. 5, $a$ ) in a similar way $j \approx I_{0}(t) /\left(2 \pi r^{2}\right), w \approx I_{0}^{2}(t) /\left(\pi^{2} \gamma r^{4}\right)$. It follows that the effect of the pulsed current flow takes place in a limited volume near the contact of the electrode with the plate. A certain characteristic may be an indicator that determines the part of thermal energy released near the electrode:

$$
d_{W}=\int_{0}^{z} w d z / \int_{0}^{\infty} w d z
$$

In Fig. 5, $b$ the dependence of the indicator on the coordinate to which the energy is taken into account, confirms the conclusion. The distribution of the field over distances has almost no effect on the total amount of heat released However, the volume where the physical processes associated with the current density can be larger than the volume where the thermal processes occur.

The temperature rise $\Delta T(z, t)$ depends on both the time and the position of the point in the volume of the plate. The value $\Delta T(z, t)$ is determined by the total amount of heat released up to the time $t$ :

$$
\Delta T(z, t)=\frac{1}{C_{p} \rho} \int_{0}^{t} w(z, \tau) d \tau .
$$


where $C_{p}$ is heat capacity, $\rho$ is density.

2. Calculation results. Calculations of mechanical effect characteristics, current density, thermalpower density and temperature rise are given for an aluminum plate with the following physical properties: $\sigma=10^{8} \mathrm{~Pa}, \quad \gamma=3.7 \cdot 10^{7} 1 /(\Omega \cdot \mathrm{m}), C_{p}=888 \mathrm{~J} /(\mathrm{kg} \cdot \mathrm{K}), \rho=2700 \mathrm{~kg} / \mathrm{m}^{3}[19]$.

The parameters of the current pulses in the winding and in the electrode are chosen so that the negative half-wave is small. Table 1 shows the initial data and the corresponding parameters of the current pulse in the inductor winding $I_{k}(t)$, and Table 2 shows similar data for the current pulse through the electrode $I_{0}(t)$.

Table 1

\begin{tabular}{|l|l|l|l|}
\hline Initial data & $t_{i m p k}=800 \cdot 10^{-6} \mathrm{~s}$ & $\Delta_{k}=10^{-1}$ & $I_{\max 1 k}=5 \cdot 10^{2} \mathrm{~A}$ \\
\hline Pulse parameters & $\beta_{k}=3.93 \cdot 10^{3} \mathrm{~s}^{-1}$ & $\alpha_{k}=2.88 \cdot 10^{3} \mathrm{~s}^{-1}$ & $I_{m k}=15.8 \cdot 10^{2} \mathrm{~A}, I_{\max k}=641 \mathrm{~A}$ \\
\hline
\end{tabular}

Table 2

\begin{tabular}{|c|c|c|c|}
\hline Initial data & 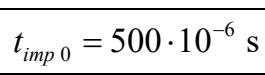 & $\Delta_{k}=10^{-1}$ & $I_{\max 10}=5 \cdot 10^{3} \mathrm{~A}$ \\
\hline Pulse parameters & $\beta_{0}=6.28 \cdot 10^{3} \mathrm{~s}^{-1}$ & $\alpha_{0}=4.61 \cdot 10^{3} \mathrm{~s}^{-1}$ & $I_{m 0}=15.8 \cdot 10^{3} \mathrm{~A}, I_{\max 0}=6410 \mathrm{~A}$ \\
\hline
\end{tabular}

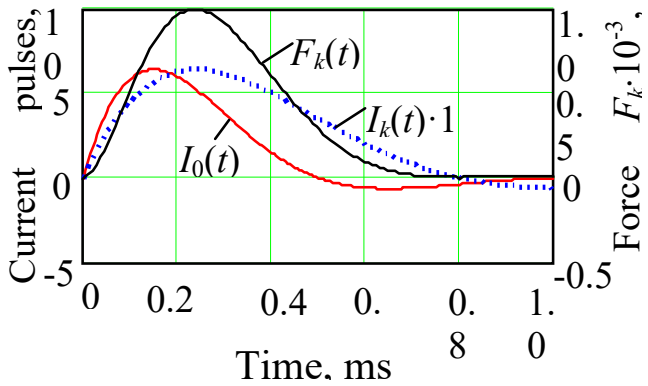

Fig. 6

The winding has $n=20$ turns and the following radial dimensions: $2 R_{1}=2 \cdot 10^{-2} \mathrm{~m}, 2 R_{2}=9,2 \cdot 10^{-2} \mathrm{~m}$.

In Fig. 6 shows the dependence of the selected current pulses on the time, as well as the force calculated by expression (6), with which the inductor acts on the shock element.

When choosing the material and thickness of the disk two circumstances must take into account. To reduce the inertia of the shock element, the mass of the disk, as the main component of its mass, should be as small as possible. The second circumstance is the need to choose the thickness of the disk under the condition of strong skin effect. Considering both positions, the disc material should have a low density and high conductivity. Aluminum meets these requirements to the greatest extent.

The thickness of the disk, as noted, is defined as $H=k_{1} \delta\left(\omega_{1}\right)$, where $k_{1}=3$ and for the selected parameters of the current pulse we have $\omega_{1}=\omega_{1}^{*} \beta_{k}=0.5 \cdot 3.93 \cdot 10^{3}=1.96 \mathrm{~s}^{-1}$. As a result, we find the thickness of the disk $H=0.014 \mathrm{~m}$ and its mass $m \approx 0.3 \mathrm{~kg}$. Given the insignificant mass of the electrode compared to the mass of the disk for the total mass of the shock element we will take the value $m=0.3 \mathrm{~kg}$. The weight of the load is $M=2.5 \mathrm{~kg}$. Electrode rounding radius $R=1.5 \cdot 10^{-2} \mathrm{~m}$.

All calculations were performed for these parameters according to the presented analytical expressions.

A. Characteristics of shock element motion. The first stage of the shock element motion up to the separation of the load is occurred for a very short period of time $t_{1 e}=2,6 \cdot 10^{-5} \mathrm{~s}$. During this period, the depth and radius of the dent are almost unchanged from the initial values $z_{0}=2.9 \cdot 10^{-6} \mathrm{~m}$, $\rho_{0}=2.96 \cdot 10^{-4} \mathrm{~m}$. This is due to the small value of force $F_{k}(t)$ during this period and the significant weight of the load.

In Fig. 7, $a$ for the entire period of time before the stop of the shock element, the dependences of the depth $z_{e}$ and radius $\rho_{e}$ of the dent on the time are presented. It can be seen that at the moment $t \approx 0.15 \mathrm{~ms}$ when the current through the electrode reaches its maximum, the dent radius does not differ much from its minimum value at the initial moment of time. It allows to get almost the maximum current density in the metal plate. This explains the choice of shorter pulse time $t_{i m p 0}$ of current $I_{0}(t)$ compared to the pulse time $t_{i m p k}$ of current $I_{k}(t)$. 
The obtained values of acceleration $a$ and velocity $v$ of the shock element (Fig. 7,b) may indicate the effectiveness of mechanical action. It is seen that the shock element reaches the maximum speed $0.2-0.3 \mathrm{~m} / \mathrm{s}$ at the time $t \approx 3 \cdot 10^{-4} \mathrm{~s}$. During motion, the maximum positive acceleration reaches the value of $1000 \mathrm{~m} / \mathrm{s}^{2}$, and the negative acceleration (braking) occurs at the time of stopping the shock element and is approximately $-2000 \mathrm{~m} / \mathrm{s}^{2}$. Such values can be quite effective without additional transmission of the current pulse through the electrode.

A certain characteristic of the impact efficiency, which is easily determined in this model representation, is the total mechanical impulse transmitted to the metal plate:

$$
Y=\rho \int_{0}^{t_{2 e}} v(t) \pi \rho_{e}^{2}(t) d z(t)=\pi \rho \int_{0}^{t_{2 e}} v^{2}(t) \rho_{e}^{2}(t) d t
$$
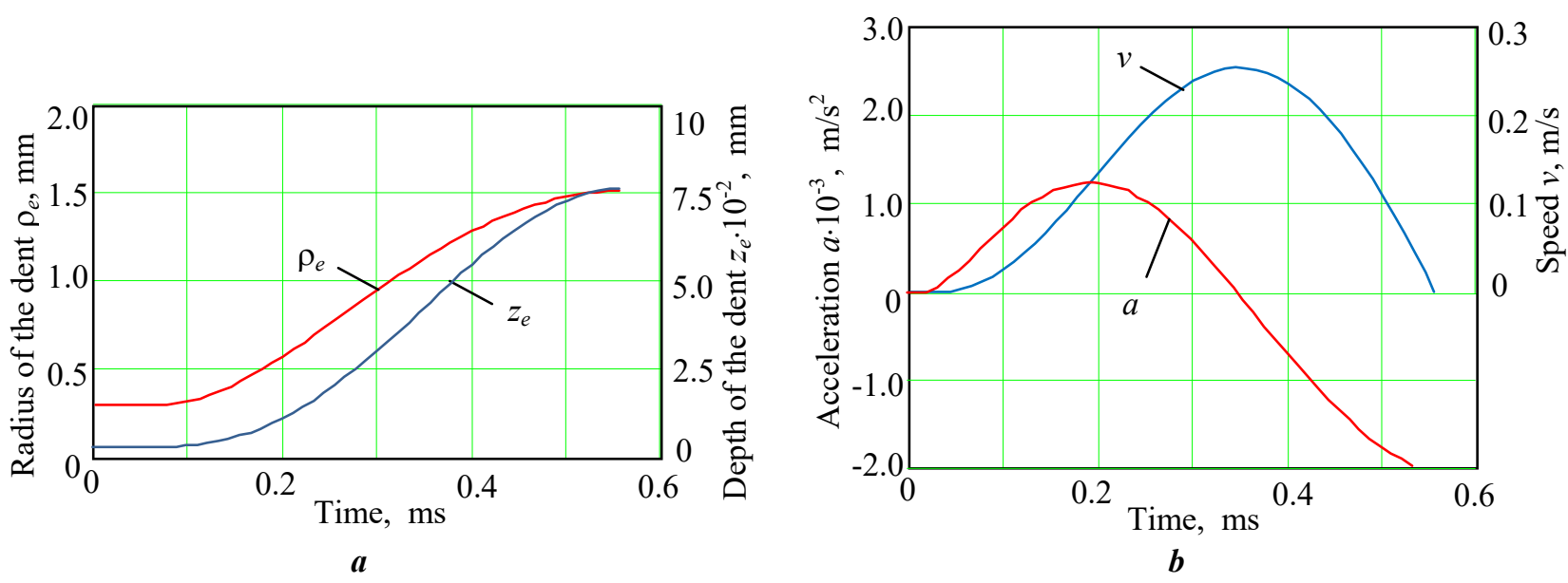

Fig. 7

Substituting all necessary values, we determine the indicator of mechanical action for this example $Y=1.49 \cdot 10^{-7} \mathrm{~kg} \cdot \mathrm{m} / \mathrm{s}$.

Another indicator may be the average value of force $\bar{Y}=Y / t_{2 e}$. For this example, we have $\bar{Y}=2.69 \cdot 10^{-4} \mathrm{~kg} \cdot \mathrm{m} / \mathrm{s}^{2}$.

These indicators can be used to compare the results of the study of systems with different electrode masses and different current pulses.

B. Processes associated with current flow in metal plate. From the point of view of the local effect on metal plate and mechanical properties of the weld, the flow of pulsed current is accompanied by the following physical processes: the achievement in a certain volume around the electrode the current density, when the electroplasticity effect occurs; heating a limited volume of the plate to a temperature at which the internal mechanical stresses decrease.

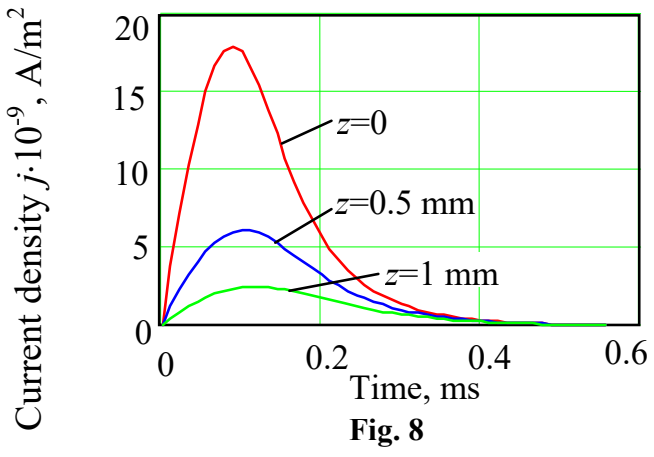

From (17) it follows that the current density $j(z, t)$ is determined both by the dependence on the time of the current pulse $I_{0}(t)$ and also by the contact radius $\rho_{e}(t)$, the value of which is defined by the electrode movement dynamics. In Fig. 8 shows graphs of time dependences of the current density $j(z, t)$ at different distances from the surface of the metal plate. The value of the current density $j \geq 10^{9} \mathrm{~A} / \mathrm{m}^{2}$, at which the effect of electroplasticity takes place, is realized for the values of the coordinate $z \leq 2 \mathrm{~mm}$ and, accordingly, for distance $r \leq 2 \mathrm{~mm}$.

With the value of the current density is related to the volumetric density of heat sources $w(z, t)$. Its dependences on time at the same values of coordinate $z$ calculated according (18) are shown in Fig. 9, $a$. The decrease with the depth of the volumetric density of heat sources is reflected in the temperature distribution to which the metal plate is heated. Fig. 9, $b$ shows the dependence of the plate temperature rise on the time at different values of the coordinate $z$. 


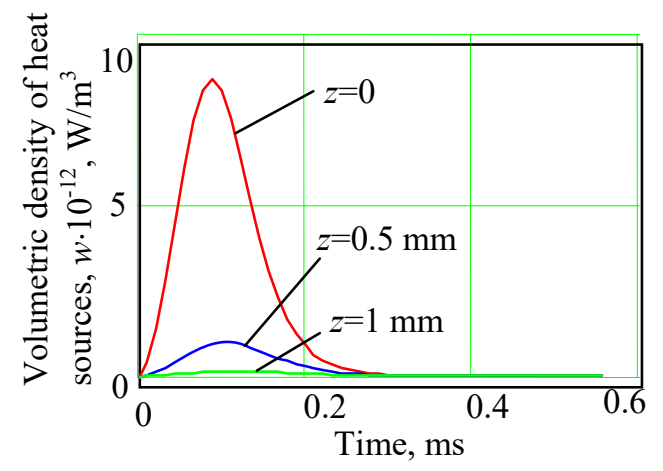

$\boldsymbol{a}$

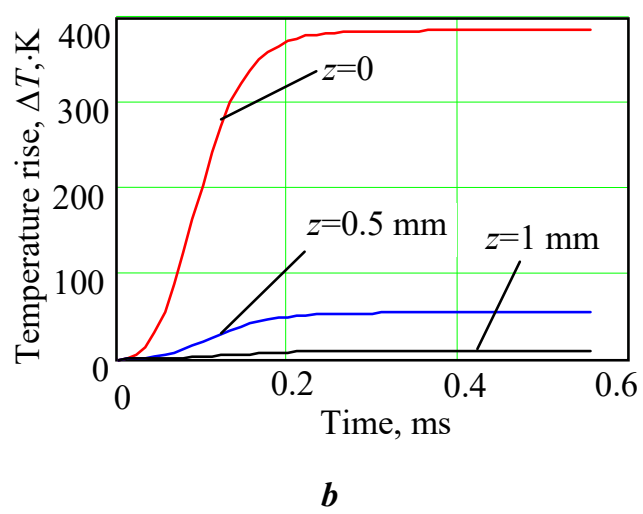

Fig. 9

It is seen that, on the one hand, to obtain any significant increase in the temperature of the metal inside the plate is not possible. Accordingly, it will be no effect on the mechanical properties in the volume. On the other hand, the heating of the surface layer is significant, in our case the temperature rise is close to $\Delta T=400 \mathrm{~K}$. At this temperature the plasticity of aluminum increases sharply. The possibility of reaching the melting point of the surface layer must be taken into account when choosing the parameters of current pulses.

Conclusion. 1. Analysis of dynamic, electromagnetic and thermal characteristics shows that the device, which implements an electrodynamic method of local influence on the mechanical properties of metal structures, especially on welds of non-ferrous metals, can be realized by simultaneously applying current pulses to the shock electromagnetic element and to the electrode, which touches a metal plate. The parameters of the mechanical system and current pulses can be selected in such a way that both the dynamic shock and the realization of the conditions for the manifestation of the electroplasticity effect are sufficiently effective.

2. From the point of view of achieving the maximum electromagnetic interaction between the magnetic field of the inductor and the conducting disk of the shock element, the parameters of the inductor current pulse, material and thickness of the disk should be chosen provided there is strong skin effect. Estimation of the manifestation of the skin effect for the pulsed magnetic field can be performed according to the entered parameters taking into account the parts of the frequency spectrum of the current pulse under conditions of strong and undesirable weak skin effect.

3. The use of the analytical mathematical model of the dynamics of the immersion of the electrode in the conducting plate for the inductor current pulse with the parameters used in the experiments, allows to determine the speed and acceleration of the shock element, which indicate the effectiveness of dynamic impact. Analysis of the increase in the contact area of the electrode makes it possible to select the parameters of the current pulse flowing through the electrode, which realizes the maximum current density near its contact with the metal plate.

4. The pulse current density in the aluminum plate, exceeding the value of $10^{9} \mathrm{~A} / \mathrm{m}^{2}$, at which the effect of electroplasticity takes place, is realized in the area, the linear dimensions of which do not exceed $2 \mathrm{~mm}$. The question of the sufficiency of such dimensions to reduce mechanical stresses across the width of the weld may be the subject of additional research. Significant heating of the plate near the contact below the melting point of aluminum occurs only for a thin surface layer of the plate, and it does not affect the mechanical properties of the material in volume.

Роботу виконано за держбюджетною темою «Розробка та виготовлення джерела імпульсного струму та виконавчого механізму комплексу для електродинамічної обробки зварних з'єднань, яка виконується в прочесі зварювання плавленням» (иифр - «Ресурс -2») иільової комплексної програми наукових досліджень НАН Украӥни “Надійність і довговічність матеріалів, конструкцій, обладнання та споруд” (КПКВК 6541230).

1. Stepanov G.V., Babutskiy A.I. Effect of High-Density Pulsed Electric Current on Strength of Metallic Materials and Stress-Strain State of Structural Components. Kyiv: Naukova dumka, 2010. 276 p. (Rus).

2. Baranov Yu.V., Troitsky O.A., Avraamov Yu.S., Shlyapin A.D. Physical fundamentals of electropulse and electroplastic treatments and new materials. Moskva: MGIU, 2001. 844 p. (Rus). 
3. Xun Liu, Shuhuai, Lan Jun Ni. Experimental study of Electro-Plastic Effect on Advanced High Strength Steels. Materials Science and Engineering: A. 2013. Vol. 582. Pp. 211-218. DOI: https://doi.org/10.1016/j.msea.2013.03.092.

4. Babutsky A., Chrysanthou A., Ioannou J. Influence of pulsed electric current treatment on corrosion of structural metals. Strength of materials. 2009. Vol. 41. No 4. Pp. 387-391. DOI: https://doi.org/10.1007/s11223-009-9142-3.

5. Moon-Jo Kim, Keunho Lee, Kyu Hwan Oh, In-Suk Choi, Hyeong-Ho Yu, Sung-Tae Hong, Heung Nam Han. Electric current-induced annealing during uniaxial tension of aluminum alloy. Scripta Materialia. 2014. Vol. 75. Pp. 58-61. DOI: https://doi.org/10.1016/i.scriptamat.2013.11.019.

6. Hui Xu, Xuebing Liu, Di Zhang, Xinfang Zhang. Minimizing serrated flow in Al-Mg alloys by electroplasticity. Journal of Materials Science \& Technology. 2019. Vol. 35. Issue 6. Pp. 1108-1112. DOI: https://doi.org/10.1016/j.jmst.2018.12.007.

7. Ming Li, Defeng Guo, Jingtao Li, Shimin Zhu, Chao Xu, Kaifang Li, Yadan Zhao, Bingning Wei, Qian Zhang, Xiangyi Zhang. Achieving heterogeneous structure in hcp $\mathrm{Zr}$ via electroplastic rolling. Materials Science and Engineering: A. 2018. Vol. 722. Pp. 93-98. DOI: https://doi.org/10.1016/j.msea.2018.02.106.

8. Grimm T.J., Mears L. Effect of power supply type on the electroplastic effect. Journal of Manufacturing Processes. 2020. Vol. 56. Part B. Pp. 1263-1269. DOI: https://doi.org/10.1016/j.jmapro.2020.04.020

9. Vasetsky Yu. M. Three-Dimensional Quasi-Stationary Electromagnetic Field of the Current Near Conducting Body. Kyiv: Pro Format, 2019. 213 p. (Rus).

10. Vasetsky Yu.M., Kondratenko I.P. Electromagnetic field of the inductor for local electric pulse effects on metal products. Tekhnichna Elektrodynamika. 2020. No $4 . \quad$ Pp. $11-14 . \quad$ (Ukr). DOI: https://doi.org/10.15407/techned2020.04.011

11. Lobanov L.M., Paschin N.A., Mykhodui O.L., Sydorenko Yu.M. Effect of the indenting electrode impact on the stress-strain state of an AMg6 alloy on electrodynamic treatment. Strength of Materials. 2017. Vol. 49. Issue 3. Pp. 369-380. DOI: https://doi.org/10.1007/s11223-017-9877-1.

12. Lobanov L.M., Kondratenko I.P., Zhiltsov A.V., Pashchin N.A., Mikhodui O.L. Development of post-weld electrodynamics treatment using electric current pulses for control of stress-strain states and improvement of life of welded structures. Materials Performance and Characterization. 2018. Vol. 7. No 4. Pp. 941-956. DOI: https://doi.org/10.1520/MPC20170092.

13. Korn G., Korn T. Mathematical Handbook for Scientists and Engineers: Definitions, Theorems, and Formulas for Reference and Review. Dover Publications, Revised edition, 2000. 1151 p.

14. Polivanov K.M. Theoretical bases of electrical engineers. Vol. 3. Electromagnetic field theory. Moskva: Energiia, 1969. 352 p. (Rus)

15. Vasetsky Yu.M. Electrodynamics. Basic concepts, potential and quasi-stationary fields. 2009. Kyiv: Vydavnytstvo Natsionalnoho aviatsiinoho universytetu NAU-DRUK, 160 p. (Rus)

16. Smirnov V.I. A Course of Higher Mathematics. Vol. 2. Elsevier, 1964. 640 p.

17. Tihonov A.N., Samarskiy A.A. Equations of mathematical physics. Moskow: Moskow University, 1999. 798 p. (Rus)

18. Simonyi K. Foundation of Electrical Engineering. Elsevier Ltd, 1963. 848 p. DOI: https://doi.org/10.1016/C20130-02694-1.

19. Encyclopedia of the Elements: Technical Data - History - Processing - Applications. John Wiley \& Sons, 2008. 1309 p. DOI: https://doi.org/10.1002/9783527612338.

\section{ДЕЯКИ ФІЗИЧНІ ПРОЦЕСИ ПІД ЧАС ЗАСТОСУВАННЯ ЕЛЕКТРОДИНАМІЧНОГО МЕТОДУ ОБРОБКИ МЕТАЛЕВИХ ВИРОБІВ}

Ю.М. Васецький, докт. техн. наук, І.П. Кондратенко, чл. -кор. НАН України

Інститут електродинаміки НАН України,

пр. Перемоги, 56, Київ, 03057, Україна,

e-mail: yuriy.vasetsky@gmail.com; dep7ied@ukr.net

На основі розробленої аналітичної математичної моделі розглянуто нестаціонарні процеси локальної електродинамічної обробки металевих виробів, пери за все зварних з'єднань, та оцінки основних динамічних, електрофізичних $і$ теплових характеристик процесу. Знайдено та проаналізовано характеристики руху електрода, розтікання імпульсного струму в металевому листі, нагрівання металу. Зроблено висновок про можливість реалізації пристроїв з одночасною подачею імпульсів струму необхідних параметрів на ударний електромагнітний елемент $i$ через електрод в металевий лист задля досягнення в ньому ефекту електропластичності. Бібл. 19, рис. 9, табл. 2.

Ключові слова: електродинамічна обробка металевих виробів, імпульс струму, рівняння руху, електропластичний ефект, нагрів металу імпульсними струмами. 